\title{
Effects of lornoxicam and intravenous ibuprofen on erythrocyte deformability and hepatic and renal blood flow in rats
}

This article was published in the following Dove Press journal:

Drug Design, Development and Therapy

3 August 2016

Number of times this article has been viewed

\author{
Hande Arpacı,** \\ Faruk Metin Çomu ${ }^{2}$ \\ Ayșegül Küçük ${ }^{3}$ \\ Bahadır Kösem ${ }^{4}$ \\ Seyfi Kartal ${ }^{4}$ \\ Volkan Șıvgın ${ }^{5}$ \\ Hüseyin Cihad Turgut ${ }^{6, *}$ \\ Muhammed Enes Aydın \\ Derya Sebile Koç 5 \\ Mustafa Arslan ${ }^{5}$ \\ 'Department of Oral and Maxillofacial \\ Surgery, Faculty of Dentistry, Ankara \\ University, Ankara, ${ }^{2}$ Department \\ of Medical Physiology, Faculty of \\ Medicine, Kırıkkale University, \\ Kırıkkale, ${ }^{3}$ Department of Medical \\ Physiology, Faculty of Medicine, \\ University of Dumlupınar, Kütahya, \\ ${ }^{4}$ Department of Anesthesiology \\ and Reanimation, Turgut Özal \\ University Hospital, ${ }^{5}$ Department \\ of Anesthesiology and Reanimation, \\ Faculty of Medicine, Gazi University, \\ ${ }^{6}$ Department of Oral and Maxillofacial \\ Surgery, Faculty of Dentistry, Gazi \\ University, Ankara, Turkey \\ *These authors contributed equally \\ to this work
}

Background: Change in blood supply is held responsible for anesthesia-related abnormal tissue and organ perfusion. Decreased erythrocyte deformability and increased aggregation may be detected after surgery performed under general anesthesia. It was shown that nonsteroidal anti-inflammatory drugs decrease erythrocyte deformability. Lornoxicam and/or intravenous (iv) ibuprofen are commonly preferred analgesic agents for postoperative pain management. In this study, we aimed to investigate the effects of lornoxicam ( $2 \mathrm{mg} / \mathrm{kg}$, iv) and ibuprofen ( $30 \mathrm{mg} / \mathrm{kg}$, iv) on erythrocyte deformability, as well as hepatic and renal blood flows, in male rats.

Methods: Eighteen male Wistar albino rats were randomly divided into three groups as follows: iv lornoxicam-treated group (Group L), iv ibuprofen-treated group (Group I), and control group (Group C). Drug administration was carried out by the iv route in all groups except Group C. Hepatic and renal blood flows were studied by laser Doppler, and euthanasia was performed via intra-abdominal blood uptake. Erythrocyte deformability was measured using a constantflow filtrometry system.

Results: Lornoxicam and ibuprofen increased the relative resistance, which is an indicator of erythrocyte deformability, of rats $(P=0.016)$. Comparison of the results from Group $\mathrm{L}$ and Group I revealed no statistically significant differences $(P=0.694)$, although the erythrocyte deformability levels in Group L and Group I were statistically higher than the results observed in Group $\mathrm{C}(P=0.018$ and $P=0.008$, respectively). Hepatic and renal blood flows were significantly lower than the same in Group C.

Conclusion: We believe that lornoxicam and ibuprofen may lead to functional disorders related to renal and liver tissue perfusion secondary to both decreased blood flow and erythrocyte deformability. Further studies regarding these issues are thought to be essential.

Keywords: rat, lornoxicam, iv ibuprofen, erythrocyte deformability, blood flow

\section{Introduction}

Erythrocytes are crucial for normal blood flow and hemodynamics. Cell deformability, aggregability, and adherence to endothelial cells are important properties of erythrocytes, which considerably affect blood flow. Under normal flow conditions with a shear stress between normal ranges, erythrocytes are dispersed and properly deformable to maintain tissue perfusion. ${ }^{1}$

However, abnormal erythrocyte properties are usually seen in various clinical situations, such as heart diseases, hypertension, diabetes, cancers, malaria, anemia, sickle cell disease, and thrombosis. ${ }^{2}$ Alterations in hemoglobin structure (inflammation, oxidative stress, and hemoglobinopathies), changes in plasma contents including albumin, fibrinogen, and other coagulation elements, as well as pathological states

\footnotetext{
Correspondence: Mustafa Arslan Department of Anesthesiology and Reanimation, Faculty of Medicine, Gazi University, Beșevler, 065I0, Ankara, Turkey

Tel +90 3122026739

Email mustarslan@gmail.com
} 
associated with diminished flow (ischemia, trauma, and surgery) are suspected underlying factors that may result in circulation deterioration. ${ }^{3}$

Nonsteroidal anti-inflammatory drugs (NSAIDs) are frequently used agents for postoperative pain, solely or in combination with other types of analgesics. NSAIDs exert their analgesic effects via inhibition of cyclooxygenase (COX) (prostaglandin synthase G2/H2) enzymes, which produce important prostaglandins (PGs) (eg, PGE1, PGE2, PGF2, and PGI2). ${ }^{4}$ However, especially in the kidney, PGs are prominent elements in regulating important processes related with blood pressure, such as salt/water balance, renin release, and vascular tone. Following the inhibition of PG synthesis by NSAIDs, salt retention, increased vascular tone in glomerular vascular bed, and decreased glomerular filtration rate may occur, and all these effects may accelerate renal failure, hypertensive disease, and end organ damage. ${ }^{5}$ Effects of NSAIDs on hepatic blood flow have not been widely investigated; however, it is well known that several PGs, such as PGE1 and PGE2, improve hepatic blood flow. ${ }^{6,7}$

In this study, we investigated the effects of two NSAIDs - lornoxicam and intravenous (iv) ibuprofen - on renal and hepatic blood flow, as well as on erythrocyte deformability, in rats.

\section{Methods}

This study was conducted in the GUDAM Laboratory of Gazi University with the consent of the Experimental Animals Ethics Committee of Gazi University. All of the procedures were performed according to the accepted standards of the Guide for the Care and Use of Laboratory Animals.

In the study, 18 male Wistar albino rats, weighing 225-280 g and raised under the same environmental conditions, were used. The rats were maintained under a temperature of $20^{\circ} \mathrm{C}-21^{\circ} \mathrm{C}$ with cycles of 12 -hour daylight and 12-hour darkness; they had free access to food until 2 hours before the anesthesia procedure.

Three groups of rats constituted the study and control groups. Six randomized rats were grouped as the control; no surgical procedure was performed on the animals in the control group and they received an equal volume of normal saline only (Group $\mathrm{C}, \mathrm{n}=6$ ). In the lornoxicam group, rats were administered lornoxicam (Xefo ${ }^{\circledR}$; Abdi İbrahim İlaç Sanayi ve Tic A.Ş, İstanbul, Turkey) $2 \mathrm{mg} / \mathrm{kg}$ intravenously (Group L). In the iv ibuprofen group, rats were administered iv ibuprofen (Intrafen ${ }^{\circledR}$, Gen İlaç ve Sağlık Ürünleri A.Ş, Ankara, Turkey) 30 mg/kg intravenously (Group I).
Two hours after administration of lornoxicam and iv ibuprofen, the rats were weighed, anesthetized with ketamine (Ketalar ${ }^{\circledR} 50 \mathrm{mg} / \mathrm{mL}$; Pfizer, İstanbul, Turkey), and euthanasia was performed via intra-abdominal blood uptake. Heparinized total blood samples were used to prepare erythrocyte packs. Deformability measurements were conducted using erythrocyte suspensions with 5\% hematocrit in phosphate-buffered saline buffer.

\section{Hepatic and renal blood flow measurement}

Hepatic and renal blood flows were recorded. Blood flow measurements were conducted using a laser Doppler microvascular perfusion monitor (OxyLab LDF; Oxford Optronix Limited, Oxford, UK) by fixing the probe on the tissue.

\section{Deformability measurements}

Erythrocyte deformability was measured using a constant-flow filtrometry system (MP 30, Biopac Systems Inc, Commat, USA). Erythrocyte suspension, delivered at $1 \mathrm{~mL} / \mathrm{min}$ flow rate, was passed through a Nuclepor ${ }^{\mathrm{TM}}$ polycarbonate filter (Thermo Fisher Scientific, Waltham, MA, USA) of $5 \mu \mathrm{m}$ diameter, and alterations in the filtration pressure corresponding to different flow rates were measured. The alterations in the pressure were transferred to a computer with an MP30 data acquisition system (Biopac Systems, Santa. Barbara, CA, USA). The ratio of the values for the filtration pressure of the cellular suspension and the buffer was calculated, and the relative resistance was thereafter calculated.

\section{Statistical analysis}

Statistical Package for the Social Sciences (SPSS Inc, Chicago, IL, USA) version 12.0 was used for statistical analysis. Erythrocyte deformability, as well as the hepatic and renal blood flows, in the study groups was assessed using the Kruskal-Wallis test. Bonferroni-adjusted Mann-Whitney $U$-test was used after significant Kruskal-Wallis results to determine which group differs from the others. Results were expressed as mean \pm standard deviation. Statistical significance was set at a $P$-value $<0.05$ for all analyses and $P<0.033$ $(0.1 / 3)$ for Bonferroni-adjusted Mann-Whitney $U$-test.

\section{Results}

Lornoxicam and ibuprofen increased the relative resistance, which is an indicator of the erythrocyte deformability, of rats $(P=0.016)$. Comparison of Group L and Group I revealed no statistically different results $(P=0.694)$, whereas Group L and Group I revealed statistically higher results than that in Group $\mathrm{C}(P=0.018$ and $P=0.008$, respectively) (Figure 1). 


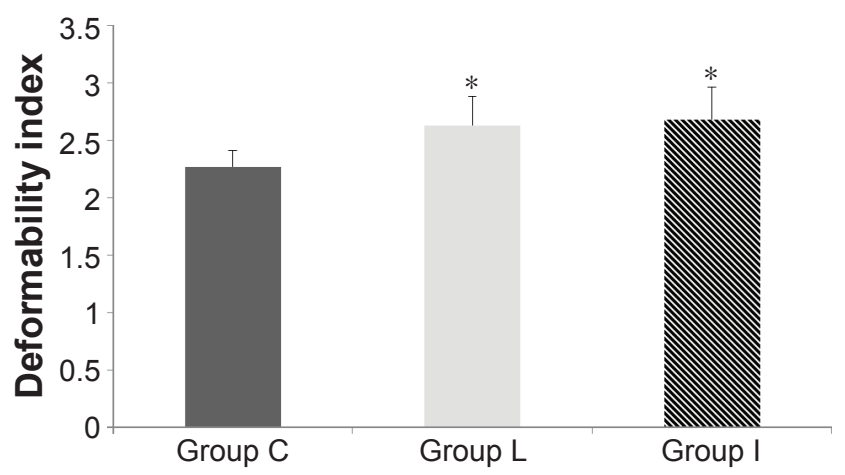

Figure I Erythrocyte deformability values of the groups.

Notes: $* P<0.05$ compared to the control group. Group I: intravenous ibuprofentreated group; Group L: lornoxicam-treated group; and Group C: control group.

Hepatic and renal blood flows were significantly lower in Group L and Group I than those measured in Group C (Figures 2 and 3, respectively) $(P=0.013$ and $P=0.016$, respectively).

Liver blood flow values in Group L and Group I were significantly lower than that in Group $C(P=0.010$ and $P=0.010$, respectively). Comparison of Group L and Group I revealed no statistically different results $(P=0.994)$.

Similarly, renal blood flow values in Group L and Group I were significantly lower than that in Group $\mathrm{C}(P=0.031$ and $P=0.006$, respectively). Comparison of Group L and Group I revealed no statistically different results $(P=0.431)$.

\section{Discussion}

In this experimental study, the effects of two different NSAIDs on erythrocyte deformability, as well as renal and hepatic blood flows, were investigated. We found that erythrocyte deformability and the renal and hepatic blood flows were significantly decreased after lornoxicam and ibuprofen

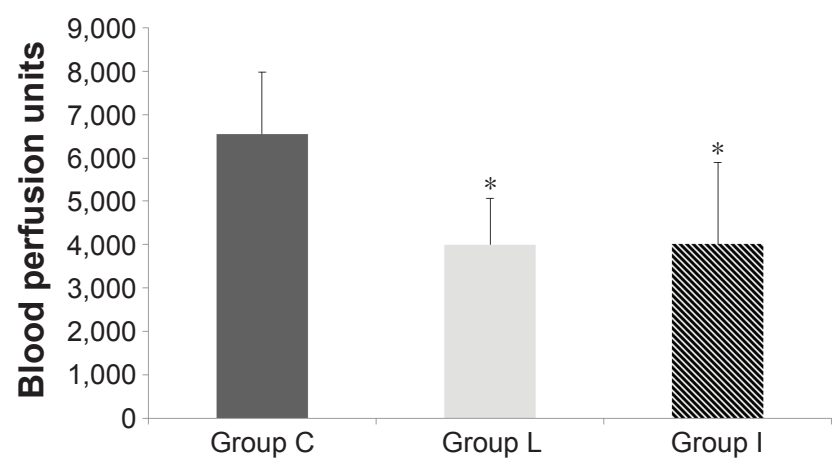

Figure 2 Distributions of liver blood flow measurements.

Notes: Measurements are represented in BPUs. $* P<0.05$ compared to the control group. Group I: intravenous ibuprofen-treated group; Group L: lornoxicam-treated group; and Group C: control group.

Abbreviation: BPU, blood perfusion unit.

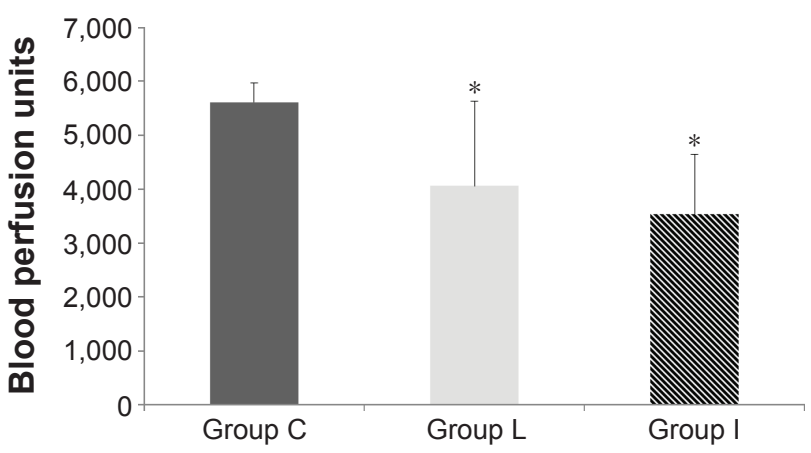

Figure 3 Distributions of renal blood flow measurements.

Notes: Measurements are represented in BPUs. ${ }^{*} P<0.05$ compared to the control group. Group I: intravenous ibuprofen-treated group; Group L: lornoxicam-treated group; and Group C: control group.

Abbreviation: BPU, blood perfusion unit.

administration when compared with the results recorded in the control group.

There are only few studies in the literature investigating the effects of NSAIDs on erythrocyte deformability. Bozzo et $\mathrm{al}^{8}$ investigated the effects of different NSAIDs (aspirin, dipyrone, ketorolac, and ibuprofen) on erythrocyte deformability and found similar erythrocyte deformability values for all NSAIDs compared with the control (dipyrone: $0.80 \pm 0.07$; ibuprofen: $0.83 \pm 0.04$; ketorolac: $0.85 \pm 0.05$; aspirin: $0.56 \pm 0.05$ ). However, they reported significantly reduced erythrocyte deformability in only the aspirin-treated group when compared with the other groups treated with different NSAIDs $(P<0.05)$. In contrast to the study conducted by Bozzo et al, iv ibuprofen and lornoxicam significantly reduced erythrocyte deformability when compared with the control in this study. In another study, Arslan et $\mathrm{al}^{9}$ compared the effects of lornoxicam and iv paracetamol on erythrocyte deformability, as well as renal and liver blood flows. They found that lornoxicam significantly reduced erythrocyte deformability when compared with iv paracetamol and control. Moreover, decreased renal and liver blood flow rates were found in the lornoxicam-treated group; however, these differences were not statistically significant.

There are two subtypes of COX enzymes; COX-1 is mainly found in the gastric mucosa, platelets, vascular endothelium, and kidney; COX-2 is substantially different from COX1 and is mainly located in monocytes and macrophages. In addition to inflammatory cells, $\mathrm{COX} 2$ may be found in smooth muscle cells, epithelial cells, and neuronal cells. Production of this enzyme is closely related with inflammatory reactions. ${ }^{10}$

Lornoxicam and ibuprofen exhibit potent inhibitory activity against both isozymes. ${ }^{11,12}$ Inhibition of these enzymes results in limited production of PGs such as PGA2, 
PGD2, PGE1, PGE2, PGF2 $\alpha$, PGI2, and thromboxane. PGs play a major role in central pain perception and pain recognition via peripheral nociceptors. The main mechanism underlying the analgesic activity of NSAIDs is the inhibition of PGs that trigger the peripheral nociceptors that recognize pain and thereby reduce inflammatory responses at the wound and/or incision site. Furthermore, in the central nervous system - both brain and spinal cord - central inhibition of COX enzymes results in reduced PG production. This process leads to decreased pain perception and hyperalgesia. ${ }^{13,14}$ On the other hand, inhibition of PGs such as PGE2 and PGI2 leads to the gastrointestinal and renal side effects of NSAIDs. ${ }^{15}$ The renal system is significantly affected, which is represented with decreased renal blood flow, increased salt retention, and renin secretion. Similar to previous studies, we found diminished renal blood flow after ibuprofen and lornoxicam administration. We suggest that these findings may be the result of decreased production of vasodilatory PGs - eg, PGE2 and PGI2 - which is a consequence of the inhibition of COX enzymes by the two NSAIDs used in the experiments.

Hepatic blood flow is less affected by the PG-mediated local effects when compared with the renal system; however, Sunose et $a{ }^{16}$ reported that increased thromboxane-A2 production by liver sinusoidal endothelial cells via increased COX-1 activity is the primary factor for the increased portal resistance and hyperresponse to vasoconstrictors. Shin et $\mathrm{al}^{6}$ showed that PGE1 improves hepatic blood flow and reduces ischemia-reperfusion injuries during liver transplantation. Similarly, the protective roles of PGI2 in liver ischemiareperfusion injury by maintaining blood flow, limiting the activity of vasoconstrictors, inhibiting local vascular thrombosis, and decreasing expression of inflammatory cytokines have been shown. ${ }^{17,18}$ We found decreased hepatic flow with administration of both NSAIDs - lornoxicam and ibuprofen - when compared with the control and we suggest that NSAID-induced inhibition of PG production may result in diminished hepatic blood flow.

We can conclude that neither iv ibuprofen nor lornoxicam is superior to each other in terms of the degree of harmful effects on erythrocyte deformability and the renal and hepatic blood flows. We suggest that the negative effects of these agents on the microcirculation, as well as the renal and hepatic blood flow parameters, have to be taken into consideration when these agents are preferred for postoperative pain management. The results of this study have to be supported with future animal and human studies.

\section{Acknowledgment}

This study was supported by a grant from the Gazi University Scientific Research Committee (number 01/2016-3).

\section{Disclosure}

The authors report no conflicts of interest in this work.

\section{References}

1. Viallat A, Abkarian M. Red blood cell: from its mechanics to its motion in shear flow. Int J Lab Hematol. 2014;36(3):237-243.

2. Popel AS, Johnson PC. Microcirculation and hemorheology. Annu Rev Fluid Mech. 2005;37:43-69.

3. Yedgar S, Koshkaryev A, Barshtein G. The red blood cell in vascular occlusion. Pathophysiol Haemost Thromb. 2002;32(5-6):263-268.

4. Johnson AG. NSAIDs and increased blood pressure. What is the clinical significance? Drug Saf. 1997;17(5):277-289.

5. Cheng HF, Harris RC. Cyclooxygenases, the kidney, and hypertension. Hypertension. 2004;43(3):525-530.

6. Shin M, Song SH, Kim JM, et al. Effectiveness of intraportal prostaglandin E1 administration after liver transplantation. Transplant Proc. 2012;44(2):500-504.

7. Ghonem N, Yoshida J, Stolz DB, et al. Treprostinil, a prostacyclin analog, ameliorates ischemia-reperfusion injury in rat orthotopic liver transplantation. Am J Transplant. 2011;11(11):2508-2516.

8. Bozzo J, Escolar G, Hernández MR, Galán AM, Ordinas A. Prohemorrhagic potential of dipyrone, ibuprofen, ketorolac, and aspirin: mechanisms associated with blood flow and erythrocyte deformability. J Cardiovasc Pharmacol. 2001;38(2):183-190.

9. Arslan M, Comu FM, Isik B, Atac MS, Yilmaz D. The evaluation of effects of lornoxicam on blood flow and erythrocyte deformability in comparison with iv paracetamol in rats. Bratisl Lek Listy. 2012;113(4): 211-213.

10. Sacerdoti D, Pesce P, Di Pascoli M, Brocco S, Cecchetto L, Bolognesi M. Arachidonic acid metabolites and endothelial dysfunction of portal hypertension. Prostaglandins Other Lipid Mediat. 2015;120:80-90.

11. Tsakiridis K, Zarogoulidis P, Vretzkakis G, et al. Effect of lornoxicam in lung inflammatory response syndrome after operations for cardiac surgery with cardiopulmonary bypass. $J$ Thorac Dis. 2014;6(suppl 1): S7-S20.

12. Moss JR, Watcha MF, Bendel LP, McCarthy DL, Witham SL, Glover CD. A multicenter, randomized, double-blind placebocontrolled, single dose trial of the safety and efficacy of intravenous ibuprofen for treatment of pain in pediatric patients undergoing tonsillectomy. Paediatr Anaesth. 2014;24(5):483-489.

13. Dirig DM, Isakson PC, Yaksh TL. Effect of COX-1 and COX-2 inhibition on induction and maintenance of carrageenan-evoked thermal hyperalgesia in rats. J Pharmacol Exp Ther. 1998;285(3):1031-1038.

14. Yaksh TL, Dirig DM, Conway CM, Svensson C, Luo ZD, Isakson PC. The acute antihyperalgesic action of nonsteroidal, anti-inflammatory drugs and release of spinal prostaglandin E2 is mediated by the inhibition of constitutive spinal cyclooxygenase-2 (COX-2) but not COX-1. J Neurosci. 2001;21(16):5847-5853.

15. Harirforoosh S, Jamali F. Renal adverse effects of nonsteroidal antiinflammatory drugs. Expert Opin Drug Saf. 2009;8(6):669-681.

16. Sunose Y, Takeyoshi I, Ohwada S, et al. The effect of cyclooxygenase-2 inhibitor FK3311 on ischemia-reperfusion injury in a canine total hepatic vascular exclusion model. J Am Coll Surg. 2001;192(1):54-62.

17. Hossain MA, Wakabayashi H, Izuishi K, Okano K, Yachida S, Maeta H. The role of prostaglandins in liver ischemia-reperfusion injury. Curr Pharm Des. 2006;12(23):2935-2951.

18. Zardi EM, Zardi DM, Dobrina A, Afeltra A. Prostacyclin in sepsis: a systematic review. Prostaglandins Other Lipid Mediat. 2007; 83(1-2):1-24. 
Drug Design, Development and Therapy

Dovepress

\section{Publish your work in this journal}

Drug Design, Development and Therapy is an international, peerreviewed open-access journal that spans the spectrum of drug design and development through to clinical applications. Clinical outcomes, patient safety, and programs for the development and effective, safe, and sustained use of medicines are a feature of the journal, which

has also been accepted for indexing on PubMed Central. The manuscript management system is completely online and includes a very quick and fair peer-review system, which is all easy to use. Visit http://www.dovepress.com/testimonials.php to read real quotes from published authors.

Submit your manuscript here: http://www.dovepress.com/drug-design-development-and-therapy-journal 